\title{
Effect of Preparation and Annealing Temperature on the Properties of $(\mathrm{Hg}, \mathrm{Tl})-2223$ Superconductor
}

\author{
Ali Alnakhlani, ${ }^{1 *}$ Belqees Hassan, ${ }^{1}$ M. A. Ahlam ${ }^{1}$ and Muhammad Abdulhafiz ${ }^{2}$ \\ ${ }^{1}$ Faculty of Sciences, Department of Physics, Ibb University, 70270 Ibb, Yemen \\ ${ }^{2}$ Faculty of Sciences, Department of Physics, Damascus University, 36822 Syria \\ *Corresponding author: ali5_2003@yahoo.com
}

Published online: 25 April 2019

To cite this article: Alnakhlani, A. et al. (2019). Effect of preparation and annealing temperature on the properties of (Hg, Tl)-2223 superconductor. J. Phys. Sci., 30(1), 71-79, https://doi.org/10.21315/jps2019.30.1.6

To link to this article: https://doi.org/10.21315/jps2019.30.1.6

\begin{abstract}
Samples of superconducting compounds were prepared by a solid-state reaction technique in a sealed quartz tube under normal pressure. The impact of the compound on the electrical properties has been studied using the electrical resistance measurements of the samples as a function of temperature. The obtained results appear that an enhancement in the phase formation, and the superconducting transition temperature $T_{c}$ were improved. It may be due to the decreasing of the magnetic impurities or the delocalisation of carriers which resulted in the enhancement of the density of mobile carriers in the conducting $\mathrm{CuO}_{2}$ planes.
\end{abstract}

Keywords: Superconducting, annealing, temperature resistance zero, mobile carriers

\section{INTRODUCTION}

Most studies on high-temperature superconductivity (HTS) have been concentrated on reaching the highest superconducting transition temperature, $\mathrm{T}_{\mathrm{c}}$. The homologous series of $\mathrm{HgBa}_{2} \mathrm{Ca}_{n-1} \mathrm{Cu}_{\mathrm{n}} \mathrm{O}_{2 \mathrm{n}+2+\delta}[\mathrm{Hg}-12(\mathrm{n}-1) \mathrm{n}]$ consists of two types of layers, i.e., charge reservoir layers (CRL) $\mathrm{HgBa}_{2} \mathrm{O}_{\mathrm{x}}$ and infinite layers (IL) $\mathrm{Ca}_{\mathrm{n}-1} \mathrm{Cu}_{\mathrm{n}} \mathrm{O}_{2 \mathrm{n}}$, where $\mathrm{n}$ is the number of $\mathrm{CuO}_{2}$ planes that exist between two CRLs and supply holes to the above-mentioned $\mathrm{CuO}_{2}$ planes. ${ }^{1}$ Concentration of charge carrier in the $\mathrm{CuO}_{2}$ planes plays an important role in high $\mathrm{T}_{\mathrm{c}}$ superconductors.

$\mathrm{T}_{\mathrm{c}}$ of $\mathrm{HgBa}_{2} \mathrm{Ca}_{\mathrm{n}-1} \mathrm{Cu}_{\mathrm{n}} \mathrm{O}_{2 \mathrm{n}+2+\delta}$ phases strongly depend on two parameters: oxygen content $(\delta)$ and number $(\mathrm{n})$ of $\left(\mathrm{CuO}_{2}\right)$ planes in their structures. ${ }^{2,3}$ The number of $\mathrm{CuO}_{2}$ planes (n) dependence of $\mathrm{T}_{\mathrm{c}}$ is an interesting problem that may bring 
important information to understand the high- $\mathrm{T}_{\mathrm{c}}$ superconductivity. Figure 1 shows the dependence of $T_{c}$ versus $n$. In this family of materials, the transition temperature sequentially increases with increasing number $\mathrm{n}$ of $\mathrm{CuO}_{2}$ planes up to $\mathrm{n}=3$, and then it is observed to decrease with further increase of $n$. Each phase has a different transition temperature to the superconducting state: for $n=1$ (1201), $\mathrm{T}_{\mathrm{C}}=97 \mathrm{~K} ; \mathrm{n}=2(1212), \mathrm{T}_{\mathrm{C}}=127 \mathrm{~K} ; \mathrm{n}=3(1223), \mathrm{T}_{\mathrm{C}}=135 \mathrm{~K} ; \mathrm{n}=4$ (1224), $\mathrm{T}_{\mathrm{C}}=126 \mathrm{~K} ; \mathrm{n}=5(1245), \mathrm{T}_{\mathrm{C}}=110 \mathrm{~K} ;$ and $\mathrm{n}=6(1256), \mathrm{T}_{\mathrm{C}}=107 \mathrm{~K}$.

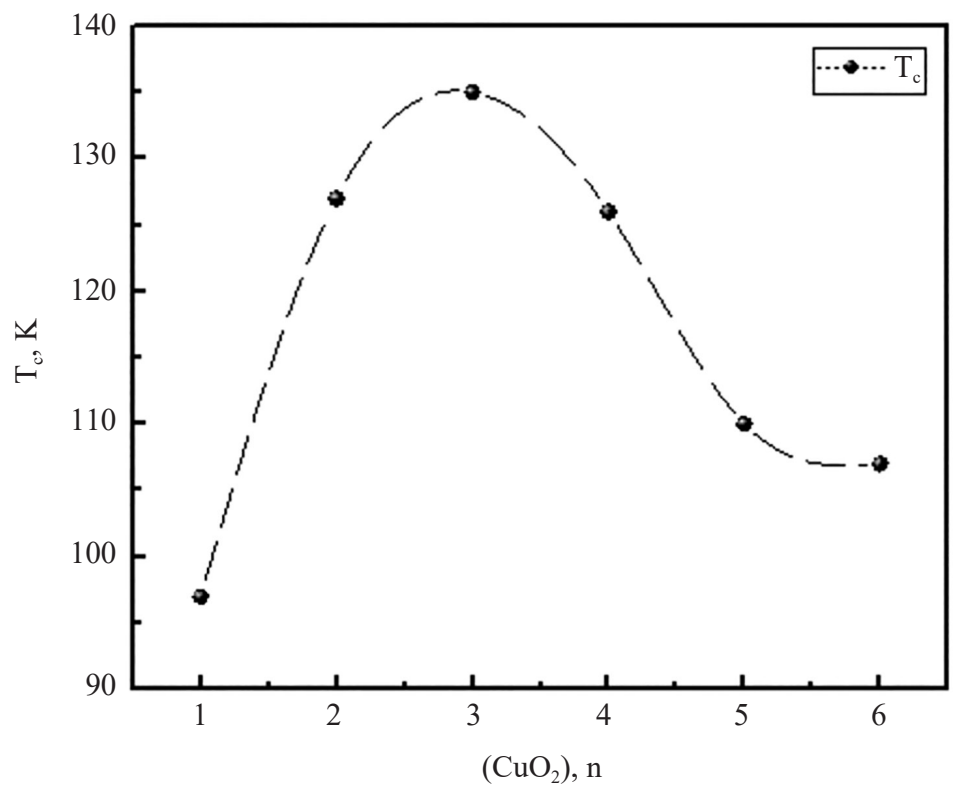

Figure 1: Variation of $\mathrm{T}_{\mathrm{c}}$ as a function of $\mathrm{n}$ for $\mathrm{HgBa}_{2} \mathrm{Ca}_{\mathrm{n}-1} \mathrm{Cu}_{\mathrm{n}} \mathrm{O}_{2 \mathrm{n}+2+\delta}$.

Previous studies on high $T_{c}$ superconductor have shown that the chemical doping or substation, preparation conditions and hole concentrations play very important roles in high $\mathrm{T}_{\mathrm{c}}$ and conventional superconductors. ${ }^{4,5}$ To improve critical transition temperature of the (Hg,Tl)-2223 compound, samples were prepared with different conditions of annealing at different temperatures. It is very important to investigate impact of varying annealing conditions on the oxygen content of the ( $\mathrm{Hg}, \mathrm{Tl})-2223$ samples. Decreasing oxygen content in the sample leads to increase in $\mathrm{T}_{\mathrm{c}}$. However, if the oxygen content increases, this allows for forming of other phases inside the sample due to the increase of the pressure inside the quartz tube. ${ }^{6}$ Thus, it is useful to observe the variation of both the superconducting properties, as well as the normal state properties of materials as a function of changing preparation, annealing temperature and time annealing in order to understand superconductivity better. 
Therefore, the aim of the current study is to synthesise and characterise the (Hg, Tl)-2223 high temperature superconductor and to investigate the effects of the preparation, annealing temperature and time annealing on the properties of these superconducting samples. The results of the present study may provide useful information to further studies of the properties of ( $\mathrm{Hg}, \mathrm{Tl})-2223$ superconductors and the optimisation of the annealing processes for $(\mathrm{Hg}, \mathrm{Tl})-2223$ superconductors.

\section{EXPERIMENTAL}

Samples with the nominal composition of $\left(\mathrm{Hg}_{0.1}, \mathrm{Tl}_{0.9}\right)_{2} \mathrm{Ba}_{2} \mathrm{Ca}_{2} \mathrm{Cu}_{3} \mathrm{O}_{8+\delta}$ were prepared by the standard solid-state reaction method in only one step. High purity (99.95\%) chemicals of $\mathrm{HgO}, \mathrm{Tl}_{2} \mathrm{O}_{3}, \mathrm{BaO}_{2}, \mathrm{CaO}$ and $\mathrm{CuO}$ were used as starting materials. These oxides were mixed using an agate mortar to make fine powder which was sieved in $64 \mu \mathrm{m}$ sieve to obtain a homogeneous mixture. The powder was pressed in discs $(1.5 \mathrm{~cm}$ in diameter and about $0.3 \mathrm{~cm}$ in thickness). Then, these discs were wrapped in a silver foil with $0.1 \mathrm{~mm}$ in thickness, which were put in sealed quartz tubes with a diameter of $1.5 \mathrm{~cm}$ and length of $15 \mathrm{~cm}$. Next, the sealed tubes were put in closed stainless steel tubes, and the stainless steel tubes were placed horizontally in a furnace. Next, they were heated at a rate of $4^{\circ} \mathrm{C}$ $\min ^{-1}$ to $\left(700^{\circ} \mathrm{C} / 811^{\circ} \mathrm{C}\right)$. The samples have been maintained at this temperature for $6 \mathrm{~h}$, and then they were cooled to room temperature at a rate of $0.5^{\circ} \mathrm{C} \mathrm{min}{ }^{-1}$. $(\mathrm{Hg}, \mathrm{Tl})-2223$ superconducting samples were annealed in normal atmosphere at $500^{\circ} \mathrm{C}$ for different time.

A closed cryogenic refrigeration system was used to perform the measurements of DC resistance for all samples with the four-probe method. The four contacts on the samples were made by a conductive silver paint. During resistance measurements a constant current of $2 \mathrm{~mA}$ has run through the sample, which was provided from a Keithely 2400 current source to avoid heating effects on the samples.

\section{RESULTS AND DISCUSSION}

Figure 2 shows behaviour of normalised resistance R (T)/R (300K) versus temperature for $(\mathrm{Hg}, \mathrm{Tl})-2223$ samples before and after annealing. It is clear that the annealed sample has a tail and its resistance zero at a temperature of $79 \mathrm{~K}$. This may be due to missing oxygen content. Figure 1 shows that the annealing has improved the phase transition and the semiconducting-like behaviour in the normal state was absent for the sample $S_{1}$. The onset temperature $\left(T_{c}{ }^{\text {onset }}\right)$ was increased from $111 \mathrm{~K}$ to $117 \mathrm{~K}$. A value of zero electrical resistance $\left(\mathrm{T}_{\mathrm{c}}{ }^{\text {offset }}\right)$ was $63 \mathrm{~K}$ before annealing, and became as $79 \mathrm{~K}$ after annealing, being higher by the annealing process. 


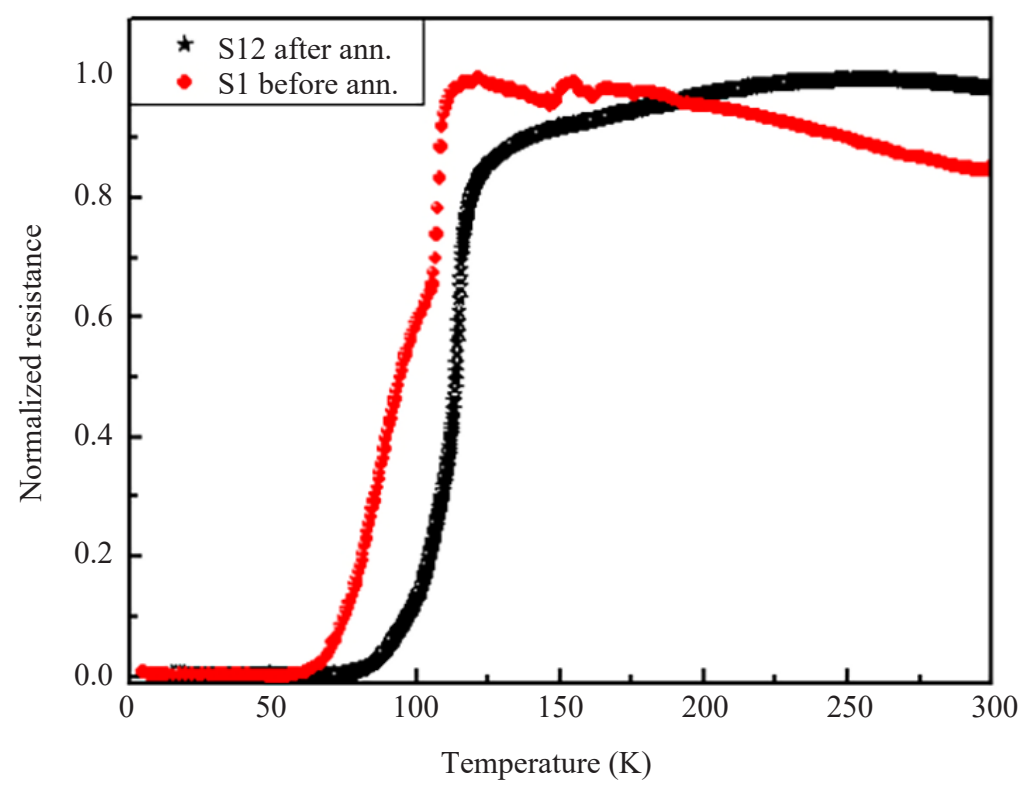

Figure 2: Normalised resistance vs. temperature characteristics for $\mathrm{S}_{1}$ samples, before $\left(\mathrm{S}_{1}\right)$ and after annealing $\left(\mathrm{S}_{12}\right)$.

There are two possibilities for enhancing $\mathrm{T}_{\mathrm{c}}$ in the (Hg, $\left.\mathrm{T} 1\right)-2223$ samples annealed under normal condition. First is by increasing of the amount of oxygen in the bulk to increase the concentration of holes in $\mathrm{p}-\mathrm{d}_{\mathrm{x}-\mathrm{y}}^{2}$ bounded. Second is possibility to reduce the amount of extra oxygen from the sample to decrease the undesired phases (magnetic, non-superconductor). It was previously reported that $\mathrm{T}_{\mathrm{c}}$ of $\mathrm{T} 1$ 2223 samples synthesised under ambient pressure was substantially enhanced by the annealing in an evacuated tube. ${ }^{7}$

Figure 3 shows the results of resistance measurements for the as-sintered samples sintered at $700^{\circ} \mathrm{C}\left(\right.$ sample $\left.\mathrm{S}_{1}\right)$ and $811^{\circ} \mathrm{C}\left(\right.$ sample $\left.\mathrm{S}_{2}\right)$ for $6 \mathrm{~h}$. Clearly, it is noticeable that the sample $S_{1}$ has two phases, but with the sample $S_{2}$, it is almost single phase. This means that the second phase has disappeared when the sample sintered at $811^{\circ} \mathrm{C}$. It is important to mention that the $\mathrm{S}_{2}$ sample was improved in connectivity and the improvement is related to the uniform distribution and alignment of superconducting grains. Also, as shown in Figure 3, the resistance decreases with temperature from $300 \mathrm{~K}$ like a metal for the $\mathrm{S}_{2}$ sample, whereas the $\mathrm{S}_{1}$ sample does not. The results of $\mathrm{R}(\mathrm{T})$ show that the sample has semiconducting-like behaviour in the normal state. This may be due to the reduced oxygen concentration in the bulk that may act as effective channelling centres of oxygen vacancies. ${ }^{8,9}$ The values of $\mathrm{T}_{\mathrm{c}}{ }^{\text {onset }}$ and $\mathrm{T}_{\mathrm{c}}{ }^{\text {offset }}$, which are determined from the electrical resistance behaviour are 
$111 \mathrm{~K}$ and $63 \mathrm{~K}$ respectively for $S_{1}$ sample, while the $T_{c}{ }^{\text {onset }}$ and $T_{c}{ }^{\text {offset }}$ for the $S_{2}$ sample are $107 \mathrm{~K}$ and $93 \mathrm{~K}$, respectively. The transition width $\Delta \mathrm{Tc}=\mathrm{T}_{\mathrm{c}}$ onset $-\mathrm{T}_{\mathrm{c}}$ offset determined from the difference between the onset temperature and zero resistance temperature for $(\mathrm{Hg}, \mathrm{Tl})-2223$ samples are listed in Table 1.

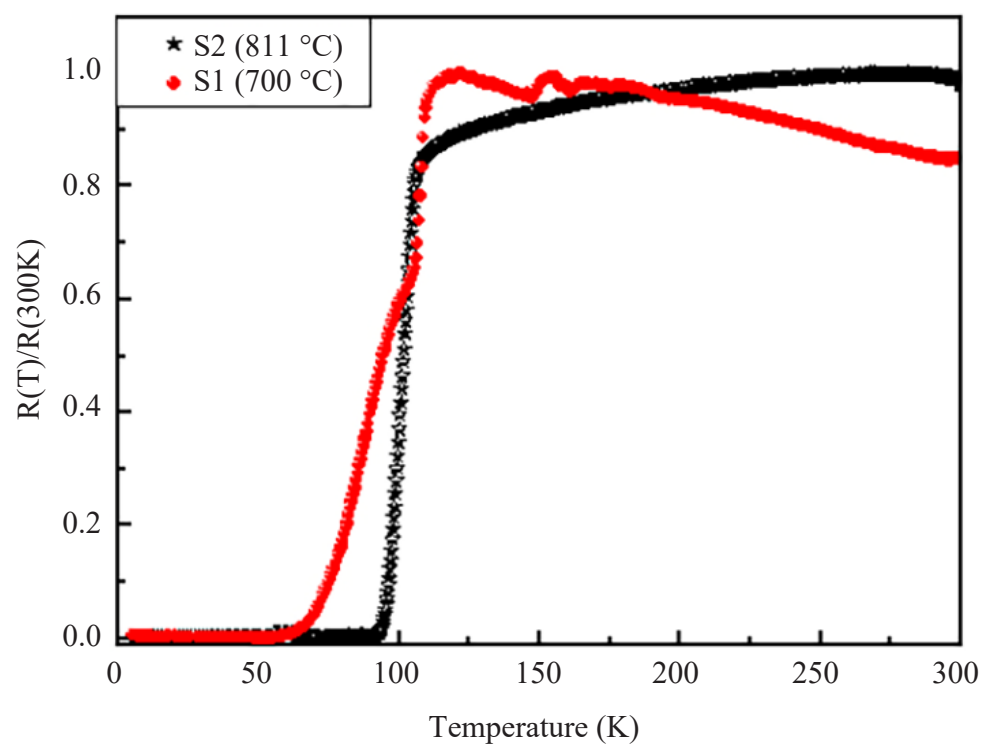

Figure 3: Temperature dependence of the normalised resistance for $(\mathrm{Hg}, \mathrm{Tl})-2223$ sample sintered at $700^{\circ} \mathrm{C}$ and at $811^{\circ} \mathrm{C}$ for $6 \mathrm{~h}$.

Figure 4 shows the temperature dependence of a normalised resistance for $S_{2}$ samples at different annealing time at $0 \mathrm{~T}$. It is observed that all samples (above the transition temperature onset ( $\mathrm{T}_{\mathrm{c}}{ }^{\text {onset }}$ ) have a linear metallic behaviour in the normal state. By decreasing the annealing time, the metallicity increases. More metallic behaviour may be attributed to the best grain connection or to optimal carrier doping in the $\mathrm{CuO}_{2}$ conducting planes of the sample under high oxygen pressure. ${ }^{10}$ $\mathrm{T}_{\mathrm{c}}{ }^{\text {onset }}$, determined from the electrical resistance behaviour when the resistance first drops, is equal to $107 \mathrm{~K}$ for $\mathrm{S}_{2}$ sample. When the sample was annealed at $500^{\circ} \mathrm{C}$ for $4 \mathrm{~h}$ (sample $\mathrm{S}_{21}$ ), $\mathrm{T}_{\mathrm{c}}$ increased by about $7 \mathrm{~K}$ to $114 \mathrm{~K}$. Further annealing at $500^{\circ} \mathrm{C}$ for $2 \mathrm{~h}$ (sample $\mathrm{S}_{22}$ ) enhanced $\mathrm{T}_{\mathrm{c}}$ up to $122 \mathrm{~K}$. It is clear that the transition width decreased with decreasing annealing time, and the annealing improved the coupling characteristics between superconducting grains. The different values for all samples determined from the resistance measurements are listed in Table 1. Annealing the samples in normal conditions leads to a decrease of resistance and to an increase of $\mathrm{T}_{\mathrm{c}}$, in agreement with the results of other studies. ${ }^{11-19}$ 


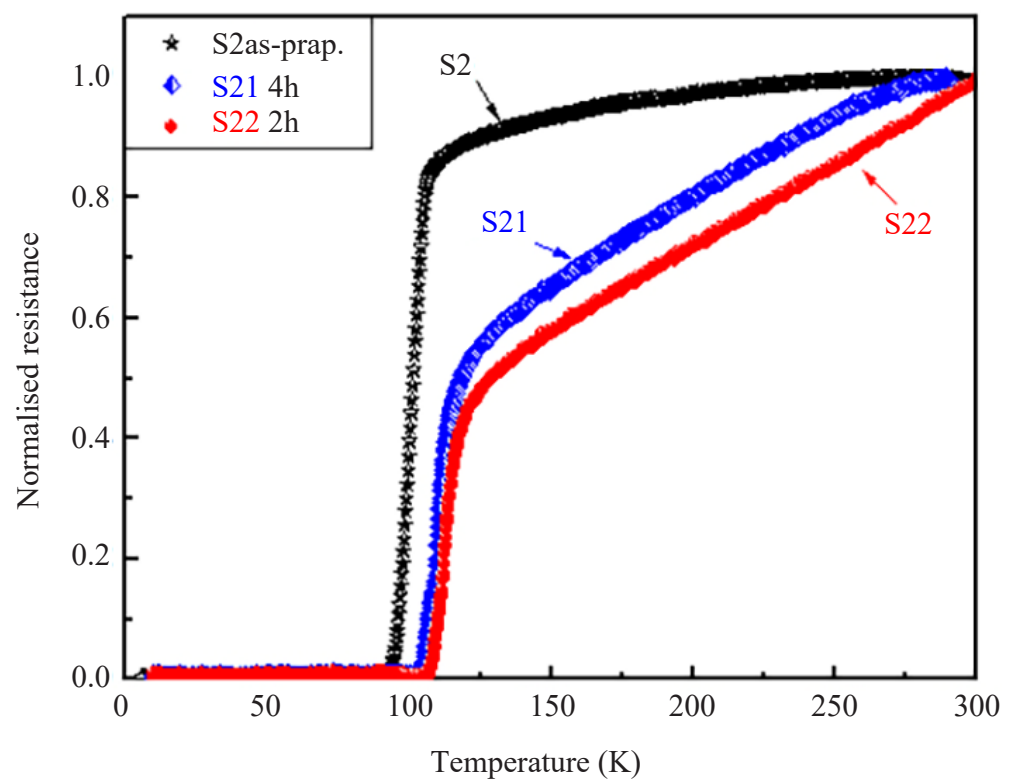

Figure 4: Normalised resistance vs. temperature measurements of $\mathrm{S}_{2}$ sample annealed at $500^{\circ} \mathrm{C}$ for $4 \mathrm{~h}$ and $2 \mathrm{~h}$.

Table 1: Sample preparation with heat treatment conditions, normal-state resistance $\left(\mathrm{R}_{300}\right)$, residual resistance $\left(R_{0}\right), T_{c}$ offset,$T_{c}{ }^{\text {onset }}$, and $\Delta T_{c}$ from resistance measurement.

\begin{tabular}{lcccccc}
\hline Samples & Annealing time $(\mathrm{h})$ & $\begin{array}{c}\mathrm{R}_{300} \\
(\Omega)\end{array}$ & $\begin{array}{c}\mathrm{R}_{\mathrm{o}} \\
(\Omega)\end{array}$ & $\begin{array}{c}\mathrm{T}_{\mathrm{c}} \text { onset } \\
(\mathrm{K})\end{array}$ & $\begin{array}{c}\mathrm{T}_{\mathrm{c}} \text { offset } \\
(\mathrm{K})\end{array}$ & $\begin{array}{c}\Delta \mathrm{T}_{\mathrm{c}} \\
(\mathrm{K})\end{array}$ \\
\hline $\mathrm{S}_{1}$ & 0 & 1.7052 & 2.22875 & 111 & 63 & 48 \\
$\mathrm{~S}_{12}$ & 4 & - & 3.00446 & 117 & 79 & 38 \\
$\mathrm{~S}_{2}$ & 0 & 0.0712 & 0.06031 & 107 & 93 & 14 \\
$\mathrm{~S}_{21}$ & 4 & 0.0378 & 0.00910 & 114 & 103 & 11 \\
$\mathrm{~S}_{22}$ & 2 & 0.0323 & 0.00458 & 122 & 112 & 10 \\
\hline
\end{tabular}

The normal-state resistance $\left(\mathrm{R}_{300}\right)$ and residual resistance $\left(\mathrm{R}_{0}\right)$ as a function of annealing time are plotted in Figure 4 for $(\mathrm{Hg}, \mathrm{Tl})-2223$ sample before and after annealing. Here, $\mathrm{R}_{300}$ is the resistance at $300 \mathrm{~K}$ and $\mathrm{R}_{0}$ is obtained from the fitting of resistance data in the temperature range $2 \mathrm{~T}_{\mathrm{c}} \mathrm{K} \leq \mathrm{T} \leq 300 \mathrm{~K}$, according to Matthiessen's rule. ${ }^{20}$

It can be observed from Figure 5 that the sample $S_{2}$ has highest room temperature resistance $R_{300}(0.0712 \Omega)$ while the sample $S_{22}$ has lowest $R_{300}(0.0323 \Omega)$. The post annealing at $500^{\circ} \mathrm{C}$ and $811^{\circ} \mathrm{C}\left(\mathrm{S}_{22}\right)$ enhances the value of resistance at $300 \mathrm{~K}$. One of the possible contributions to the room temperature resistance is 
from the defects present in the samples. The defects may be due to the presence of impurities and weak links between the superconducting grains. ${ }^{21}$ During annealing, the oxygen content and thus the density of mobile carriers of the superconducting phase could increase, giving rise to a decrease in resistance. ${ }^{22}$ After annealing in normal conditions, the $S_{22}$ sample had a critical temperature $T_{c}$ onset $=122 \mathrm{~K}$ with a transition width $\Delta \mathrm{T}_{\mathrm{c}}=10 \mathrm{~K}$. It may be due to the decreasing of the magnetic impurities or the delocalisation of carriers which results in the increase of the holes concentration in the conducting $\mathrm{CuO}_{2}$ planes.

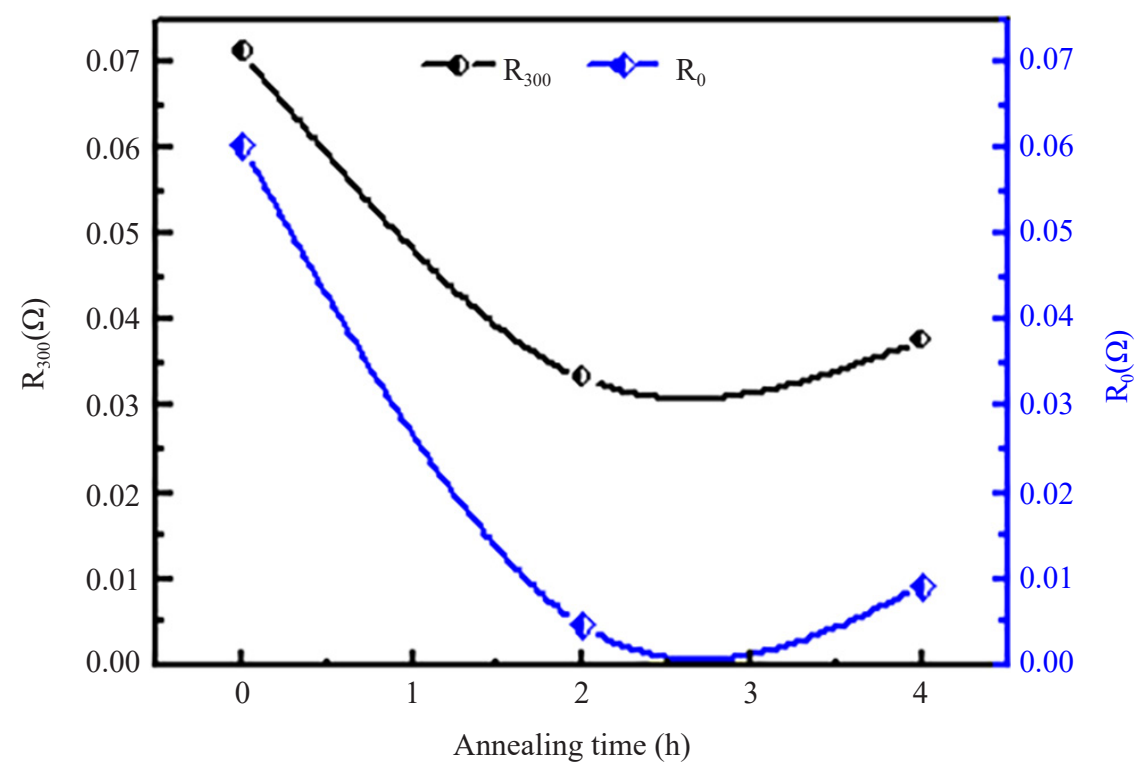

Figure 5: The $\mathrm{R}_{300}$ and the $\mathrm{R}_{0}$ as a function of annealing time for $(\mathrm{Hg}, \mathrm{Tl})-2223$ sample.

\section{CONCLUSION}

The current study has investigated theinfluence of preparation, annealing temperature and time annealing on the properties of the $(\mathrm{Hg}, \mathrm{Tl})-2223$ superconductor $\left(\mathrm{T}_{\mathrm{c}}\right.$ onset and $T_{c}{ }_{c}$ offet $)$. The results of $R(T)$ measurements have shown that the optimised annealing temperature is $811^{\circ} \mathrm{C}$ for $2 \mathrm{~h}$. The highest $\mathrm{T}_{\mathrm{c}}$ of $\mathrm{S}_{22}$ sample in this study was $T^{\text {onset }}=122 \mathrm{~K}$ and at $T_{c}{ }^{\text {offset }}=112 \mathrm{~K}$. The increased pressure inside the quartz tube allows the formation of other phases inside the sample when the samples were annealing in air (normal conditions). The inter-grain superconductivity in (Hg, Tl)-2223 samples may be significantly affected by the time and the annealing temperature. 


\section{ACKNOWLEDGEMENTS}

The authors would like to thank the anonymous reviewers for their valuable comments and suggestions to improve the quality of the paper. This work was supported by Ibb University, Yemen and Damascus University, Syria.

\section{REFERENCES}

1. Shivagan, D. et al. (2008). AC-susceptibility study on vortex-molecule lattice in supermultilayer cuprate $\mathrm{HgBa}_{2} \mathrm{Ca}_{\mathrm{n}-1} \mathrm{Cu}_{\mathrm{n}} \mathrm{O}_{2 \mathrm{n}+2+\delta}(\mathrm{n}=14)$. Phys. C, 468(15), 12811286, https://doi.org/10.1016/j.physc.2008.05.213.

2. Antipov, E. V., Abakumov, A. M. \& Putilin, S. N. (2002). Chemistry and structure of Hg-based superconducting Cu mixed oxides. Supercond. Sci. Technol., 15(7), R31, https://doi.org/10.1088/0953-2048/15/7/201.

3. Iyo, A. et al. (2006). Synthesis and physical properties of multilayered cuprates. Phys. C Supercond. App., 445, 17-22, https://doi.org/10.1016/j.physc.2006.03.067.

4. Liang, B. et al. (2002). Effect of vacuum annealing on the structure and superconductivity of $\mathrm{Bi}_{2} \mathrm{Sr}_{2} \mathrm{CaCu}_{2} \mathrm{O}_{8+\delta}$ single crystals. Phys. C Supercond., 366(4), 254-262, https://doi.org/10.1016/S0921-4534(01)00910-8.

5. Terzioglu, C., Varilci, A. \& Belenli, I. (2009). Investigation of effect of annealing temperature on mechanical properties of $\mathrm{MgB}_{2}$. J. Alloys Comp., 478(1-2), 836841, https://doi.org/10.1016/j.jallcom.2008.12.044.

6. Ali Yusuf, A. et al. (2011). Effect of $\mathrm{Ge}^{4+}$ and $\mathrm{Mg}^{2+}$ doping on superconductivity, fluctuation induced conductivity and interplanar coupling of $\mathrm{TlS}_{2} \mathrm{CaCu}_{2} \mathrm{O}_{7-\delta}$ superconductors. Phys. C Supercond., 471, 363-372, https://doi.org/10.1016/j. physc.2011.03.007.

7. Tatsuki, T. et al. (1997). Annealing study on $\left(\mathrm{Hg}, \mathrm{Tl}_{2} \mathrm{Ba}_{2} \mathrm{Ca}_{\mathrm{n}-1} \mathrm{Cu}_{\mathrm{n}} \mathrm{O}_{\mathrm{y}}(\mathrm{n}=1-5)\right.$ superconductors. Phys. C Supercond., 278(3-4), 160-168, https://doi.org/10.1016/ S0921-4534(97)00117-2.

8. Martynova, O. A. \& Gasumyants, V. E. (2008). On the transformation of the normal-state band spectrum of Tl-based HTSC's with increasing number of $\mathrm{CuO} 2$ layers and doping level. Phys. $C, 468,394-400$, https://doi.org/10.1016/j. physc.2007.12.007.

9. Abbas, M. M., Abass, L. K. \& Salman, U. (2012). Influences of sintering time on the $\mathrm{T}_{\mathrm{C}}$ of $\mathrm{Bi}_{2-\mathrm{x}} \mathrm{Cu}_{\mathrm{x}} \mathrm{Pb}_{0.3} \mathrm{Sr}_{2} \mathrm{Ca}_{2} \mathrm{Cu}_{3} \mathrm{O}_{10+\delta}$ high temperature superconductors. Energy Proced., 18, 215-224, https://doi.org/10.1016/j.egypro.2012.05.033.

10. Gao, L. et al. (1993). Study of superconductivity in the Hg-Ba-Ca-Cu-O system. Phys. C Supercond., 213(3-4), 261-265, https://doi.org/10.1016/09214534(93)90440-2.

11. Khan, N. A., Husnain, G. \& Sabeeh, K. (2006). Enhanced superconductivity in $\mathrm{Cu}_{0.5} \mathrm{Tl}_{0.5} \mathrm{Ba}_{2} \mathrm{Ca}_{\mathrm{n}-1-\mathrm{y}} \mathrm{Be}_{\mathrm{y}} \mathrm{Cu}_{\mathrm{n}} \mathrm{O}_{2 \mathrm{n}+4-\delta}(\mathrm{n}=3,4$ and $\mathrm{y}=0.7,1.5,1.7,2.0)$ system with oxygen doping. J. Phys. Chem. Solids, 67(8), 1841-1849, https://doi. org/10.1016/j.jpcs.2006.04.010. 
12. Carrasco, M. F. et al. (2006). Annealing time effect on Bi-2223 phase development in LFZ and EALFZ grown superconducting fibres. Appl. Surf. Sci., 252(14), 49574963, https://doi.org/10.1016/j.apsusc.2005.07.025.

13. Hirai, M. et al. (2007). Annealing effect on Tc in the multi-layered cuprate superconductor $(\mathrm{Cu}, \mathrm{C}) \mathrm{Ba}_{2} \mathrm{Ca}_{4} \mathrm{Cu}_{5} \mathrm{O}_{\mathrm{y}}$. Phys. C Supercond. App., 460-462, 450-451, https://doi.org/10.1016/j.physc.2007.03.183.

14. Irfan, M. \& Khan, N. A. (2010). Study of phonon modes and superconducting properties of the oxygen post-annealed $\left(\mathrm{Cu}_{0.5} \mathrm{Tl}_{0.5}\right) \mathrm{Ba}_{2} \mathrm{Ca}_{\mathrm{n}-1}\left(\mathrm{Cu}_{\mathrm{n}-\mathrm{y}} \mathrm{Ge}_{\mathrm{y}}\right) \mathrm{O}_{2 \mathrm{n}+4-\delta}(\mathrm{n}=3$, 4 and $\mathrm{y}=0,0.5,0.75,1.0)$ superconductors. Cryogen., 50(2), 61-65, https://doi. org/10.1016/j.cryogenics.2009.11.001.

15. Wang, X. G., Huang, Z. \& Yuan, L. (1995). Effect of F-doping in the HgBa-Ca-Cu-O system. Phys. C Supercond., 253(3-4), 254-258, https://doi. org/10.1016/0921-4534(95)00527-7.

16. Shao, H. M. et al. (1997). Optimization and enhancement of transition temperature for $\mathrm{HgBa} 2 \mathrm{Ca} 2 \mathrm{Cu} 3 \mathrm{O} 8+\delta$ ceramic superconductors. Phys. C Supercond., 282-287, 1559-1560, https://doi.org/10.1016/S0921-4534(97)00925-8.

17. Ha, D. H. et al. (2000). Effects of Sr substitution on $\mathrm{T}_{\mathrm{c}}$ of $\mathrm{Y}_{0.85} \mathrm{Ca}_{0.15} \mathrm{Ba}_{2-\mathrm{x}} \mathrm{Sr}_{\mathrm{x}} \mathrm{Cu}_{3} \mathrm{O}_{\mathrm{y}}$. Phys. C Supercond., 341-348, 607-608, https://doi.org/10.1016/S09214534(00)00611-0.

18. Shen, Z. et al. (2013). Electrospinning preparation and high-temperature superconductivity of $\mathrm{YBa}_{2} \mathrm{Cu}_{3} \mathrm{O}_{7-\mathrm{x}}$ nanotubes. J. Mater. Sci., 48(11), 3985-3990, https://doi.org/10.1007/s10853-013-7207-y.

19. Kajitani, J. et al. (2014). Correlation between crystal structure and superconductivity in $\mathrm{LaO}_{0.5} \mathrm{~F}_{0.5} \mathrm{BiS}_{2}$. Solid State Commun., 181, 1-4, https://doi.org/10.1016/j. ssc.2013.11.027.

20. Awad, R. et al. (2008). Superconducting properties of zinc substitution in Tl2223 phase. J. Alloys Comp., 460(1-2), 500-506, https://doi.org/10.1016/j. jallcom.2007.05.100.

21. Khurram, A. A. et al. (2011). Effect of ion irradiation induced defects on the excess conductivity of $\mathrm{Cu}_{1-\mathrm{x}} \mathrm{Tl}_{\mathrm{x}} \mathrm{Ba}_{2} \mathrm{Ca}_{1} \mathrm{Cu}_{2} \mathrm{O}_{8-\delta}$ superconductor thin films. Phys. $C$ Supercond., 471(1-2), 35-41, https://doi.org/10.1016/j.physc.2010.10.007.

22. Aytug, T. et al. (1999). Effect of sodium doping on the oxygen distribution of Hg-1223 superconductors. Phys. C Supercond., 313(1-2), 121-126, https://doi.org/10.1016/S0921-4534(98)00699-6. 